\title{
Transparency Initiative for Enhancing QoL: Behavioural components leading to corruption
}

\author{
Roshana Takim, Shazwan Mohamed Shaari, Rumaizah Mohd Nordin \\ Faculty of Architecture, Planning and Surveying, \\ Universiti Teknologi MARA (UiTM) Shah Alam, 40450 Malaysia \\ rumaizah.mnordin@gmail.comc
}

\begin{abstract}
Transparency is an essential precondition for containing corruption. Construction is prone to corruption as it involves a large number of participants. Corruption is a deviant behaviour of an individual that should be looked into. The objective of this paper is to study the behavioural factors that lead to corrupt acts based on the Model of Corrupt Action. Questionnaire survey is utilised to derive to the solution. The results show that behavioural factors concerning the achievement of a certain goal do not predict corrupt action but the desire factors represent an important antecedent of intention by which a strong predictor of particular behaviour.
\end{abstract}

Keywords: Transparency Initiative (TI); Model of Corrupt Action; corruption; construction

eISSN 2398-4279 @ 2018. The Authors. Published for AMER ABRA cE-Bs by e-International Publishing House, Ltd., UK. This is an open-access article under the CC BY-NC-ND license (http://creativecommons.org/licenses/bync-nd/4.0/). Peer-review under responsibility of AMER (Association of Malaysian Environment-Behaviour Researchers), ABRA (Association of Behavioural Researchers on Asians) and cE-Bs (Centre for EnvironmentBehaviour Studies), Faculty of Architecture, Planning \& Surveying, Universiti Teknologi MARA, Malaysia.

DOI: https://doi.org/10.21834/ajqol.v3i9.90 


\subsection{Introduction}

Transparency is directly linked to integrity; a person with integrity opens themselves up for the scrutiny of others and is transparent with regards to their actions (Gebel, 2012). Most importantly, transparency is an essential precondition for containing corruption, as it renders abuse of power and increases the likelihood of detection. Notably, through transparency, accountability and economic efficiency is raised. When processes are transparent, lawmakers, regulators and civil servants are made to be accountable for their decisions (Lopez, 2007).

Construction industry is large, pervasive and acts as the bellwether of economic growth. Periods of national prosperity are usually associated with high level of construction activity (Clough et al, 2000). The construction process requires the contribution of many different stakeholders and involves various processes, different phases of work, and a great deal of inputs from both the public and private sectors (Abdul-Aziz and Mohmad, 2010). Nevertheless, one of the challenges facing the industry is notoriety for corruption (Jong et al, 2009). Construction is prone to corruption since it is fragmented, involves a large number of participants in a complex contractual structure that leads to a variety of psychological human behaviour and attitude inclining towards corrupt activities (Stansbury, 2005; Mohd-Nordin, et al., 2012). Corrupt practices can be found at every phases of construction projects that leads to devastating consequences on the quality of the built environment, project delivery period, and competitive performance of the industry (Sohail and Cavill, 2006; Murray and Meghii, 2009).

Corruption is a deviant behaviour which manifests itself in an abuse of function such as in politics, economy, institution, and in favour of another person for the fact that temptation for corruption could exist everywhere. An 'inclination' for corruption is conceived to be intrinsic to human nature, and yet needs permissiveness, opportunities and incentives (Rabl and Kuhlmann, 2008; Gebel, 2012). A great deal of effort has been done to fight corruption in order to turn the industry towards prosperity with greater equity and give life to sustainable development. Sustainable development is a device to enhance quality of life; healthy environment; and improve social, economic and environment conditions for the present and future generations (Ortiz et al., 2009). According to the chairman of Transparency International; Peter Eigen, "corruption in public projects is a daunting obstacle to sustainable development, and results in major loss of public funds" (Sultan and Kajewski, 2005). Thus, the objective of this paper is to study the behavioural components that lead to corruption based on the 'Model of Corrupt Action' for sustainable development.

\subsection{Problem Statement}

Transparency is generally defined as the open flow of information; subsume accountability in public discourse of good governance and acts as practical measures to curtail corruption (Park and Blekinsopp, 2011). According to Kolstad and Wiig (2008) there is a correlation between a lack of transparency and high levels of corruption. A higher level of transparency in decision making increases the probability that corruption or wrongdoing is detected.

Construction is one of the most lucrative sectors despite construction projects being regarded as intricate and time consuming (Murray \& Meghji, 2009). Nevertheless, the 
construction sector is perceived as one of the most corrupt sector of the economy of any country across the globe. The notion of sustainable development in construction by improving the social, economic, environment and entrancing integrity could help to build a more sustainable future (Ortiz et al, 2009).

According to Mohd-Nordin et al (2012), higher transparency can reduce the opportunities of corrupt acts. In order to be transparent, individual need to instil themselves with ethics and good values such as honesty. These good values are the elements of integrity that comprises from social psychological behaviour. They emphasised that one of the source of corruption is due to influence for luxurious lifestyle that leads public officials to use their discretionary power for their private satisfaction. This situation will affect the actual quality of life (QOL) of an individual. QOL is regarded as individuals' perception of their position in life in the context of culture and values which is related to their goals, expectations, standards and concerns (World Health Organisation, 1997). It is a broad ranging concept affected in a complex way by the person's physical health, psychological state, level of independence, social relationships, personal beliefs and their relationship to salient features of their environment. Corruption should be treated both the technical (insufficient legislation) and behavioural factors of the institutions (Gebel, 2012). This is due to the fact that corruption occurs as a form of behaviour violating the official ethics of public services, a stem of social norms that emphasize gift-giving and loyalty to family or clan, rather than the rule of laws (Park and Blenkinsopp, 2011; Montinola \& Jackman, 2002).

Figure 2 introduces a Model of Corrupt Action. The model examines the person-based determinants of human behaviour in interaction with a specific situational context (Rabl \& Kuhlmann, 2008). This model is developed based on Model of Effortful Decision Making and Enactment (MEDME) by Bagozzi et al (2003) that integrates Rubicon Model of Action Phases (RMAP) (Gollwitzer, 1990) and Theory of Planned Behaviour (TPB) (Ajzen, 1991) as shown in Figure 1.

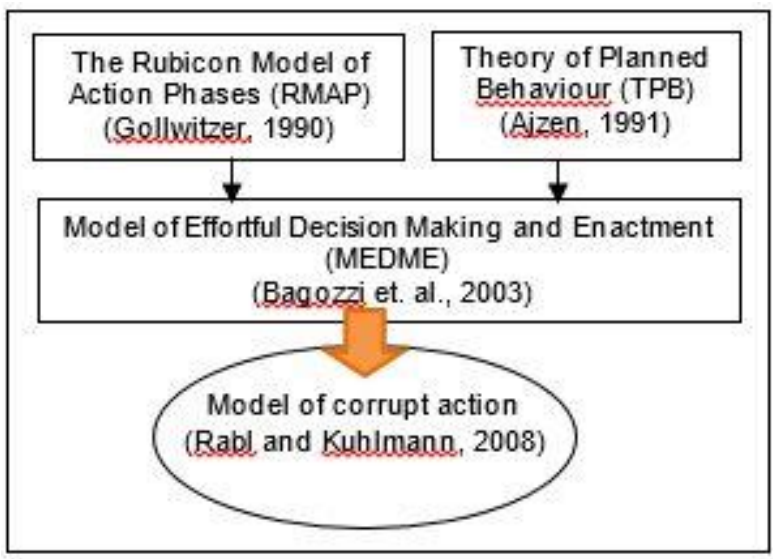

Figure 1: The development of Model of Corrupt Action (Source: Rabl and Kuhlmann (2008) 


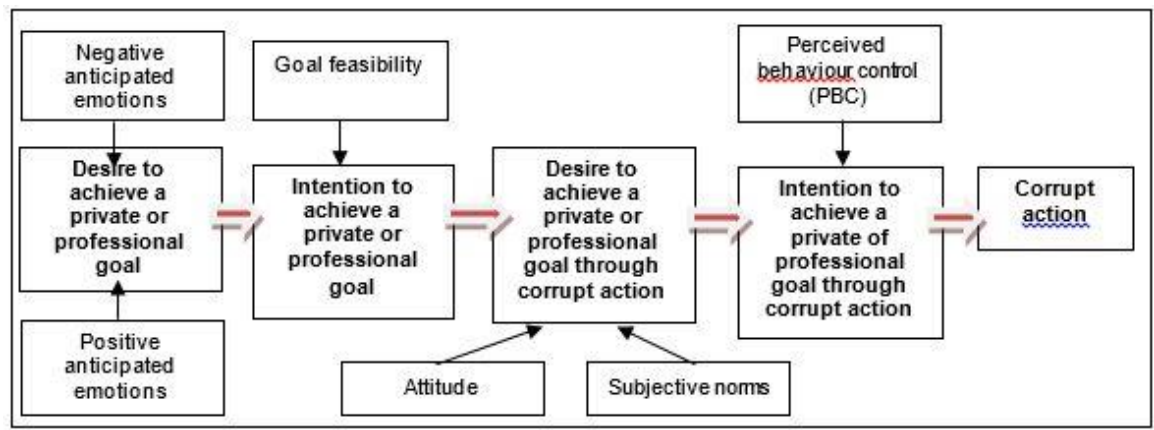

Figure 2: The Model of Corrupt Action

(Source: Rabl and Kuhlmann (2008)

The combination of these two models (RMAP and TPB) has developed the MEDME by which it is necessary due to three factors: (1) TPB does not specify clearly the relationship between intention and behaviour which have been tackled by RMAP through volition construct, (2) TPB does not incorporates desires as a determinant intention to perform an action, and (3) both TPB and RMAP do not consider emotional aspects (Rabl and Kuhlmann, 2008). The MEDME distinguishes between intentions and desires, and shows that the motivation-mustering function of the decision process is mediated by goal and implementation desires. On top of that, the role of goal feasibility, anticipated emotions, attitudes, subjective norm, and perceived behavioural control are also considered. In MEDME, intention represents the proximal determinant of action in model of goal-directed behaviour while desires are necessary antecedents to intention formation (Bagozzi et al, 2003).

Based on the ideas of Gollwitzer (1990), Ajzen (1991) and Bagozzi et al (2003) provide an input to the full Model of Corrupt Action by Rabl and Kuhlmann (2008). The Model of Corrupt Action consists of two main components the 'desire' and 'intention' to achieve through corrupt actions. According to the model, the desire to achieve a private or professional goal depends on the positive and negative emotions anticipated with regard to goal attainment. These emotions have motivating power and trigger decisions as part of a general process of self-regulation. The desire to achieve private or professional goal has to be transformed into an intention since desires are necessary antecedents to intention. In order to achieve the goal, people tend to consider the difficulties or opportunities available. The lower the goal feasibility the higher the strength of intention will be. The desirability of corrupt action as a way to achieve the private or professional goal is caused by goal intention.

For non-routine goal, the goal intention and implementation intention are based on deliberative process considering the desirability and feasibility of achieving the goal. Whether the implementation intentions are actually formed depends on the anticipation of difficulties which is termed as perceived behaviour control (PCB). PCB is assumed to reflect past experiences and anticipated impediments and obstacle. Hence, the stronger an individual's intention to perform the particular behaviour the greater will be the outcomes of PCB. Finally, 
whether the intention is transformed into action is depending on the volitional strength. The stronger the person is committed to a certain way of achieving a goal, the more likely the relevant actions are actually initiated (Gollwitzer, 1990). Since, there has been little research focussing on the person who acts corruptly, the objective of this research is to investigate the behavioural factors that lead to corrupt action by utilising the Model of Corrupt Action.

\subsection{Methodology}

This research utilised a questionnaire survey method based on the seven behavioural factors of Model of Corrupt Action. To measure these factors, a-ten-points Likert type scaled items were deployed for which the participants were asked to indicate their level of agreement and disagreement. A non-probability of judgement purposive sampling is used based on the expertise of respondents on the subject matters. For the purpose of this research, stakeholders involved are: client (the Government, or in this case JKR), public authorities, and contractors.

As shown in Table 1, a total number of 71 questionnaires were sent out to the three target groups (Government, public authorities, and contractors of a CIDB SCORE 4-star) within the construction industry over a period of two months. Out of these, 13 questionnaires were completed and returned representing a response rate of $18.31 \%$ which is acceptable in construction management research (Dulami et al. 2003). Eight respondents $(53.33 \%)$ were from government sectors, followed by two (14.28\%) from public authorities and three $(7.14 \%)$ from contractors. The poor response rate from contractors is could be due to the frequent public holidays and limited time frame allocated for the data collection. The range of experience of the respondents in terms of number of years in the construction industry is between 5-7 years, representing an executive level of experience in the sample. The outcomes of the questionnaire were analysed by using Statistical Package for Social Science (SPSS) for descriptive statistics and non-parametric Spearman correlation.

Table 1: Response Data

\begin{tabular}{lllc}
\hline Type of organisations & \multicolumn{2}{c}{ Number of questionnaires } & $\begin{array}{c}\text { Percentage return } \\
\text { non }\end{array}$ \\
\cline { 2 - 3 } & Sent & Return & (\%) \\
\hline Government: Public Work Department & 15 & 8 & 53.33 \\
Public Authorities: Municipal Council & 14 & 2 & 14.28 \\
Contractors & 42 & 3 & 7.14 \\
\hline \multicolumn{1}{l}{} & & & \\
\hline Total & 71 & 13 & 18.31 \\
\hline
\end{tabular}

\subsection{Findings and Discussions}

\subsection{Reliability of Data}


Reliability can be assessed in a number of different ways. Cronbach's Alpha is the most common method of examining reliability in term of internal consistency. The calculation of Cronbach's Alpha is based on number of items and the average inter-item correlation. It ranges from ' 0 ' for a complete unreliable test to ' 1 ' for completely reliable test (Hinton et al, 2004). Pallant (2001) suggests the value for alpha should be greater than 0.7 for the scale to be reliable with the sample. Nunnally (1978) suggests that the modest reliability scale is in the range of 0.50-0.60, while Hinton et al. (2004) and Takim (2005) consider moderately reliable scale in the range of $0.5-0.75$. Table 2 shows the results for the reliability based on the Cronbach's Alpha value. The results presented show that the Cronbach's Alpha is in the range of $0.52-0.73$ showing that the data collected are interrelated and reliable.

Table 2: Reliability of Data

\begin{tabular}{l|c|c}
\hline Behavioural factors & $\begin{array}{c}\text { Cronbach's } \\
\text { Alpha }\end{array}$ & $\begin{array}{c}\text { No. of } \\
\text { items }\end{array}$ \\
\hline 1. Desire to achieve a private or professional goal & 0.73 & 3 \\
2. Intention to achieve a private or professional goal & 0.54 & 4 \\
3. Goal feasibility & 0.72 & 3 \\
4. Desire to achieve a private or professional goal through corrupt action & 0.52 & 2 \\
5. Intention to achieve a private or professional goal through corrupt action & 0.54 & 3 \\
6. Perceived behavioural control (PBC) & 0.83 & 3 \\
7. Corrupt acts* & - & - \\
\hline
\end{tabular}

${ }^{* *}$ The construct was measured by a single item

\subsection{Descriptive statistics}

Descriptive statistic is the method of analysis which provides a general overview of the result. The most common descriptive statistics used are frequency distribution, measurement of central tendency and measurement of dispersion (Naoum, 1998; Hinton et al, 2004). Table 3 presents the descriptive analysis of this research. Close observation reveals that the 'desire to achieve a private or professional goal' (mean=6.06)' correspond to the 'desire to achieve private or professional goals through corrupt action' (mean=7.69). Meanwhile, the mean value for the 'intention to achieve a private or professional goal' (mean=3.46) match the 'intention to achieve a private or professional goal through corrupt action (mean=5.08). The outcomes suggest that 'desires' and 'intentions' are the key words of behavioural factors responsible for corrupt actions. A desire is often classified as an emotion that induce consumers; while intention is the specific purpose in performing an action; the end or goal that is aimed at. In this case, both mean values of 'desires' are high compared to the values of 'intention' indicating that emotions are detrimental feature to sustainable development. 
Nevertheless, the intention to corrupt behaviour could be control if the actor has positive attitudes towards integrity.

Table 3: Descriptive statistics

\begin{tabular}{llccc}
\hline Behavioural factors & & Mean & $\begin{array}{c}\text { Standard } \\
\text { Deviation }\end{array}$ \\
\hline 1. & Desire to achieve a private or professional goal & 13 & 6.06 & 1.80 \\
2. Intention to achieve a private or professional goal & 13 & 3.46 & 2.48 \\
3. Goal feasibility & 13 & 5.00 & 2.00 \\
4. Desire to achieve a private or professional goal through corrupt action & 13 & 7.69 & 2.18 \\
5. Intention to achieve a private or professional goal through corrupt & 13 & 5.08 & 1.66 \\
$\quad$ action & & & 1.50 \\
6. Perceived behavioural control (PBC) & 13 & 8.31 & 1.48 \\
7. Corrupt acts & 13 & 1.77 & \\
\hline
\end{tabular}

Another factor that need to be highlighted is 'perceived behavioural control' (PBC) with the mean value of 8.31. PBC it used in order to explain behaviour over which people have incomplete volitional control. For corrupt action PBC can be due to the likelihood of detection and the extent of penalties. Ajzen (1991) emphasised that the stronger the individual intention to perform the behaviour under consideration, the greater the PBC. This is in line with the results in Table 3 indicating that the mean value of 'intention to achieve a private or professional goal through corrupt action' (mean value $=5.08$ ) is greater due to the effect of PBC compared to mean value of intention to achieve a private or professional goal (mean value=3.46), without through corrupt action.

Finally, the intention facilitates the initiation of goal-directed behaviour of the specified situation or opportunities through corrupt action. This means that the stronger the intention to achieve private or personal goal through corrupt action, the more likely the corrupt action will be. Unfortunately, the mean value of corrupt action (mean=1.77) appeared to be very small, which is contradicted to the mean value for intention to achieve a private or professional goal through corrupt action (mean=5.08). The possible reason for this predicament could be due to respondents that deliberately fake the results in order to make them look good (Rees and Metcalfe, 2002).

\subsection{Non-parametric Spearman correlation}

A correlation is performed to test the degree to which the scores of the two variables corelates. According to Pallant (2011), correlation provides an indication that there is a 
relationship between two variables, however it did not indicate that one variable causes another. Spearman correlation is used to correlate ordinal data that is not normally distributed (Hinton et al, 2004). A strong correlation indicates that there is only a small amount of error and most of the points lie close to the regression line; whilst a weak correlation indicates that there is a lot of error and the points are more scattered. Cited in Pallant (2011) and Cohen (1988) suggested that small $r=.10$ to .29 , medium $r=.30$ to .49 , and large $r=.50$ to 1.0 .

Table 4 shows the results of the correlation among the behavioural factors. It can be seen that there is a strong positive correlation between 'desire to achieve a private or professional goal' and 'intention to achieve a private or professional goal' (rho $=0.561$ ). This is in line with Rabl and Kuhlmann (2008) that desire in achieving certain goals has to be transformed into intention. This means that, the higher the desire individual have to achieve their private or professional goal, the higher the intension will be.

Table 4: Correlation between behavioural factors

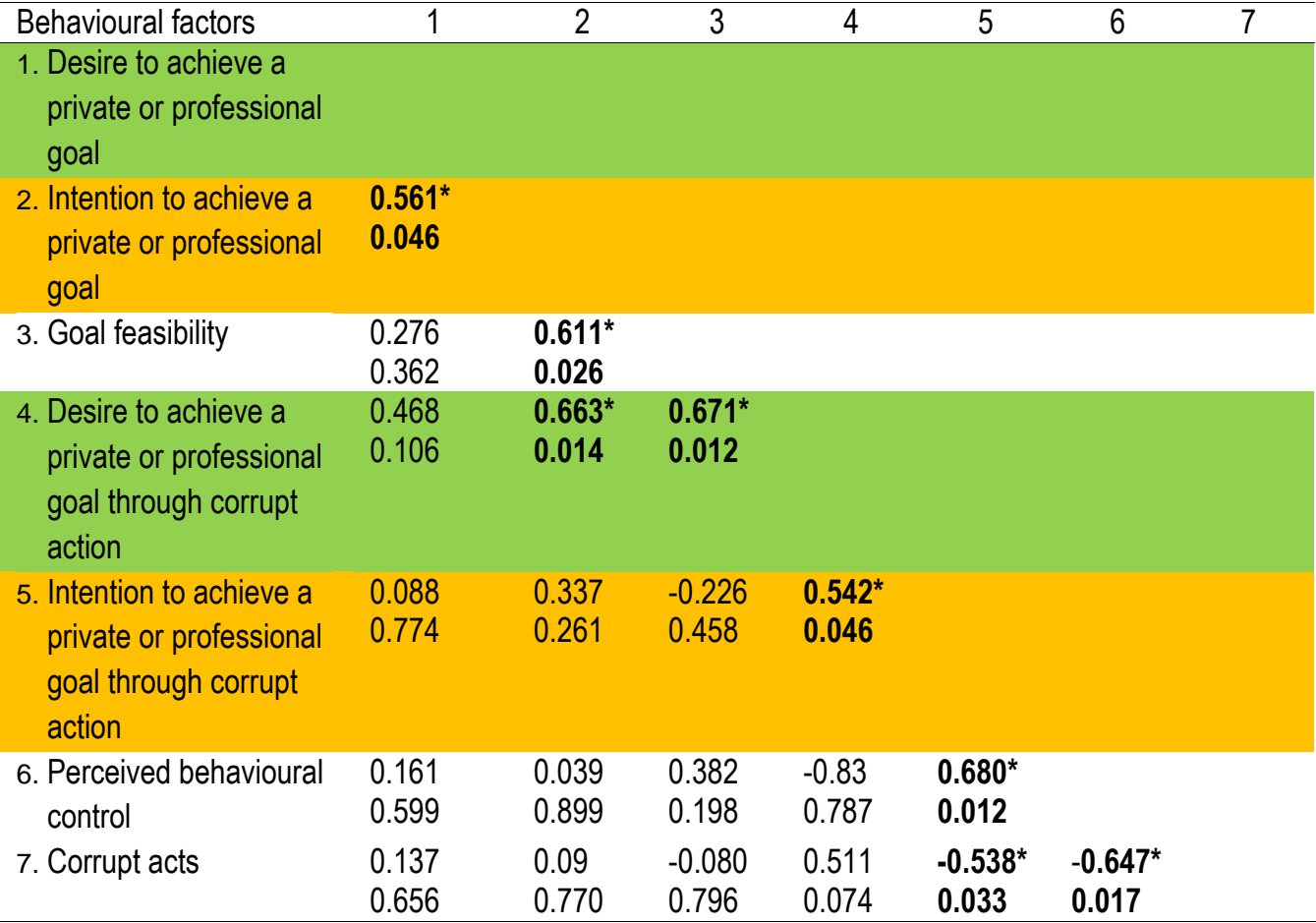

*Significant at 0.05

The next factor is goal feasibility. The 'goal feasibility' has a strong positive correlation with 'intention to achieve a private or professional goal and desire to achieve a private or professional goal through corrupt action'. This implies that the more feasible the targeted 
goal is, the stronger people intend to achieve it. According to Gollwitzer (1990) goal feasibility is the ability to achieve the goal whether necessary means or opportunities available and the situational context is facilitating or impeding. When a goal intention is formed, a plan to achieve the goal is developed and in this case is through corrupt action. Since goal feasibility effect intention, it will also affect the desirability of corrupt action as a way to achieve the targeted goal.

Moreover, a positive correlation between 'goal feasibility and desire to achieve a private or professional goal through corrupt action' (rho $=0.663$ ) transpired. It supports the previous statement by Bagozzi et al (2003) stating that implementation desires are caused by goal intention, depending on the anticipation of difficulties. Therefore, PBC is referred to perceived ease or difficulty of performing the behaviour (Ajzen, 1991). Once again based on the result, PBC has a strong positive correlation towards 'intention to achieve a private or professional goal through corrupt action' (rho=0.680). This implies that the higher the $\mathrm{PBC}$, the stronger the intention for corrupt acts which is in line with Ajzen (1991) and Bagozzi et al (2003). Despite the 'intention to achieve a private or professional goal through corrupt action' is a strong predictor for corrupt act (Rabl and Khulmann, 2008), the result is contradicted when negative correlation (rho $=-0.538$ ) occurred between the two variables. This may be due to the personality of the respondents that fake their answer although to a certain extent fakinggood in responding questions are considered unethical (Rees and Metcalfe, 2003).

Other than that, the results show that there is a negative correlation between PBC corrupt acts (rho=-0.647) which is also contradicted with (Rabl \& Kuhlmann, 2008). This shows that a lower PBC may increase the likelihood of corrupt act. However, PBC is not a direct dependent variable to corrupt action and PBC have only medium effect towards intention to achieve a private or professional goal through corrupt action. The overall summary of the results is illustrated in Figure 3.

\subsection{Conclusion}

This paper has presented the findings on the behavioural factors that lead to corrupt action based on the Model of Corrupt Action by Rabl and Kuhlmann (2008). The results revealed that the behavioural factors such as desire to achieve a private or professional goal; intention to achieve a private or professional goal; and goal feasibility do not allow for prediction of corrupt act due to no correlation exist between them. Meanwhile, the intention to achieve a private or professional goal through corrupt action and PBC has a direct correlation to corrupt acts but appear to be negatively related. This shows that specificity of a certain situation is necessary in predicting contextual behaviour as in this case corrupt action which effected by intention to achieve private or professional goals through corrupt action that affected by desire to achieve private or professional goals through corrupt action. Tannsjo (2010) emphasised that there are not only moral reasons for certain actions but reasons to desire certain things may mislead us. Since desire depends on individual emotions, there is a tendency that particular emotions being 'fitting' or 'appropriate' for certain situation. One example from Tang and Liu (2012), corruption form unfair environment. Due to that, unfair outcomes evoke greater activation in emotional area of the brain thus people engage in 
unethical behaviour in the name of justice. Intentions on the other hand are mental states that represent an action we want and prefer to be realised based on proper deliberation of good means and moral will (Lumer, 2012). This prove that, even though desire will influence intention, to a certain extent the intention will reduce due to control factors such as motivations, laws, regulations and values of the individuals. Despite according to Ajzen (1991), intention is a predictor for behaviour the results shows the opposite. As mentioned earlier, this might be due to the respondents' personality that intentionally fakes the answer so that they will look good. Apart from that, a larger sample may be required to obtain a more generalise result since the sample of this study is small.

As the behavioural factors that lead to corrupt acts are identified, prevention of corruption based on the psychological focus should be given proper attention. This may include corruption-aversive subjective norm through adopting ethical environment; cooperation from top management; integrity test and measuring corruption-relevant attitude during employee selection; use of rewards and sanctions; and establish effective control mechanism to maximise the risks of corrupt actors (Rabl and Kuhlmann, 2008). These variables require a further research to be conducted comprehensively to identify the suitable measures for corrupt actions in construction to improve the quality of life.

The research presented in this paper is part of an ongoing $\mathrm{PhD}$ research study at the Faculty of Architecture, Planning and Surveying, UiTM to develop a framework of transparency initiative for public construction projects in Malaysian construction industry. The result of the study could provide an insight into Malaysian construction project environment and could offer a valuable guideline, in particular to respective industry players that are looking forward for a more transparent construction market.

\section{Acknowledgement}

The authors would like to acknowledge the contribution from the Universiti Teknologi MARA (UiTM) through supporting the research with Excellence Fund (RIF).

\section{References}

Abdul-Aziz, A.-R., and Mohmad, M.-D. (2010). Project manager competencies in undertaking construction project. Seri Iskandar, Perak.

Abdul-Rahman, H., Wang, C., and Yap, X. W. (2010, December 4). How Professional Ethics Impact Construction Quality: Perception and Evidence. Scientific Research and Essays, 5(23), 3742-3749.

Ajzen, I. (1991). The Theory of Planned Behaviour. Organisational Behaviour and Human Decision Process, 179211.

Bagozzi, R. P., Dholakia, U. M., and Basuroy, S. (2003). How effortful decdisions get enacted: The motivating role of decision processes, desires, and anticipated emotions. Journal of behavioural decision making, 273-295.

Lumer, C. (2012). The volitive and executive fuction of intention. Philosophy Studies 
Clough, R. H., Sears, G. A., and Sears, S. K. (2000). Construction Project Management (4th ed.). Canada: John Wiley \& Sons.

Dulami, M. F., Ling, F. Y. Y., and Bajracharya, A. (2003). Organisational motivation and inter-organisational interaction in construction innovation in Singapore. Construction Management and economics, 21pp307-318.

Francis, J. J., Eccles, M. P., Johston, M., Walker, A., Grimshaw, J., Foy, R., et al. (2004). Construction the questionnaires based on the Theory of Planned Behaviour: A Manual for Health Services Researchers. United Kingdom: Quality of Life and Management of Living Resources,University of Newcastle .

Gebel, A. C. (2012). Human nature and morality in the anti corruption discourse of Transparency International. Public Administration and Development, 32, 109-128.

Gollwitzer, P. M. (1990). Action Phases and Mindsets. In E. T. Higgins, \& R. M. Sorrentino, Handbook of Motivation and Cognition: Foundations of social behaviour (Vol 2) (pp. 55-62). New York: The Guildford Press.

Hinton, P. R., Brownlow, C., McMurray, I., and Cozens, B. (2004). SPSS Explained. New York: Routledge. Jong, M. d., Henry, W. P., and Stansburry, N. (2009, July). Eliminating corruption in Our Engineering/Construction Industry. Leadership and Management in Engineering, pp. 105-111.

Kolstad, I., and Wiig, A. (2009). Is Transparency the Key to Reducing Corruption in Resource-Roch Countries? World Development, 37(3), 521-532.

Lopez, G. P. (2007). Transparency Key to National Integrity. Malaysia: The Star.

Loughman, B. P., and Sibery, R. A. (2012). Bribery and Corruption: Navigating the global risks. New Jersey: John Wilye \& Sons, Inc.

Mohd-Nordin, R., Takim, R., and Nawawi, A.-H. (2012). Transparency Initiatives (TI) in Construction: The Social Psychology of Human Behaviours. ASEAN Conference on Environment-Behaviour Studies. Bangkok: Elsevier.

Montinola, G. R., and Jackman, R. W. (2002). Sources of corruption: cross-country study. British Journal of Political Sciences, 32(1), 147-170.

Murray, M., and Meghji, M. R. (2009). Corruption within International Engineering-Construction Projects. Retrieved June 15, 2010, from http://217.197.210.21/resources/integrity/meghii construction_oct08.pdf

Naoum, S. G. (1998). Dissertation research and writing for construction students. Oxford: Butterworth-Heinemann. Nunnally, I. (1978). Psychometric Theory. New York: McGraw-Hill.

Ortiz, O., Castells, F., and Sonnemann, G. (2009). Sustainability in the construction industry: A reveiew of recent developments based on LCA. Construction and Building Materials, 28-39.

Pallant, J. (2001). SPSS Survival Manual: A step by step guide to data analysis using SPSS for windows (Version 10-11). Buckingham: Open University Press.

Pallant, J. (2011). SPSS Survival Manual: A step by step guide to data analysing using SPSS (4th Ed). Australia: Allen and Unwin.

Park, H., and Blenkinsopp, J. (2011). The roles of Transparency and Trust in the Relationship between Corruption and Citizen Satisfaction. International Review of Administrative Sciences, 77(2), 254-274. 
Rabl, T., and Kuhlmann, T. M. (2008). Understanding corruption in organisations - Development and empirical assessment of an Action Model. Journal of Business Ethics, 477-495.

Rees, D. J. and Metcalfe, B. (2002). The faking of personality, questionnaire results: who's kidding whom? Journal of Managerial Psychology, 18(22), 156-165.

Rovers, R. (2003, April - September). The role of policies in promoting sustainable practices. UNEP Industry and Environment, pp. 29-32.

Sohail, M., and Cavill, S. (2006). Corruption in Construction Projects. CIB W 2006. United Kingdom.

Spies, E., and Wittmann, A. (1999). Motivational phases associated with the foreign placement of managerial candidates: an application of the Rubicon model of action phases. Human Resource Management, 891-905.

Stansbury, N. (2005). Exposing the Foundations of Corruption in Construction. United Kingdom: Transparency International.

Sultan, B., and Kajewski, S. (2005). Policies for economic sustainability for the construction industry in Yemen. Queensland University of Technology Research Week International Conference. Brisbane: Sidwell, Anthony, Eds.

Tang, T. L and Liu, H. (2012). Journal of Business Ethics, 107, 295-312

Tannsjo, T. (2010). Reasons to desire. Library of Ethics and applied philosophy, 22, 125-149

World Health Organisation, W. (1997). WHOQOL Measuring Quality of Life. Division of Mental Health and Prevention of Substance Abuse. 